\title{
A tradução como prática crítica: usando a retradução no ensino da tradução ${ }^{1}$
}

\author{
Jonathan Evans* \\ Tradução de Marcia A.P. Martins**
}

A questão de como a teoria e a prática da tradução se inter-relacionam é um enigma para o ensino dos Estudos da Tradução. Como observa Dorothy Kelly, há uma percepção de que grande parte da pesquisa sobre tradução, sobretudo na modalidade literária, não tem relevância imediata para os aprendizes de tradução (2005, p. 114-5). Este artigo se propõe a fornecer uma resposta para a pergunta: "Como associar teoria e prática nas aulas de tradução?" Não se pretende que seja uma resposta definitiva, mas uma entre tantas que podem ser discutidas e consideradas a critério dos professores de tradução. ${ }^{2}$

Minha sugestão gira em torno de ensinar retradução como uma atividade prática e da ideia de tradução como uma "prática crítica", subscrevendo o emprego dessa expressão por Elspeth kydd (2011) com relação a filmes. A retradução, que defino aqui como a tradução de um texto para a língua-meta com pleno conhecimento de uma tradução anterior para a mesma língua-meta, não tem inspirado tantos textos críticos voltados especificamente para o tema quanto a tradução. Uma pesquisa da BITRA

\footnotetext{
${ }^{1}$ Artigo originalmente publicado em inglês em Quaderns. Revista de Traducció 21, 2014, p. 199-209.

${ }^{*}$ Universidade de Glasgow, Escócia, RU

** Pontifícia Universidade Católica do Rio de Janeiro

2 Uma versão anterior deste trabalho foi apresentada na 12th Portsmouth Translation Conference "Those Who Can Teach", em novembro de 2012. Agradeço aos organizadores pela oportunidade de apresentálo, e ao público pelos comentários sobre as minhas ideias.
} 
(Bibliografia de Interpretação e Tradução) ${ }^{3}$ registra 127 textos sobre retradução, enquanto que a base de dados da publicação Translation Studies Abstracts $^{4}$ lista 37 textos $^{5}$. De modo geral, a retradução tem sido estudada com foco nos textos literários (ver, por exemplo, MONTI; SCHNYDER, 2011; DEANE-COX, 2011; O'DRISCOLL, 2011) e dramáticos (por exemplo, AALTONEN, 2003), embora também tenha recebido alguma atenção com referência à filosofia (por exemplo, SUSAM-SARAJEVA, 2003), aos textos científicos (como XU, 2003) e aos documentos institucionais (por exemplo, KOSKINEN; PALOPOSKI, 2003). Essa diversidade de abordagens à retradução poderia sugerir que esta não pode ser limitada a um único domínio do conhecimento ou gênero textual. No entanto, como observou Enrico Monti (2011, p. 10), não há um verbete para retradução no Dictionary of Translation Studies ou na primeira edição da Routledge Encyclopedia of Translation Studies, embora a segunda edição venha corrigir essa lacuna (TAHIR GÜRÇAGLAR, 2009). É possível argumentar, portanto, que a retradução não é percebida como um conceito central do campo disciplinar da tradução. Tal situação se faz refletir na quase total ausência da retradução na literatura voltada para a formação de tradutores: não está presente no sumário de A Handbook for Translator Trainers (2005), de Dorothy Kelly, nem em muitos outros volumes sobre o ensino da tradução (BAKER, 2011; DOLLERUP; LODDEGAARD, 1992; GILE, 1995; GONZÁLEZ DAVIES, 2004; HUNG, 2002; KEARNS, 2008; KUSSMAUL, 1995; ROBINSON, 2012 etc.). Don Kiraly (2000, p. 66) menciona brevemente a retradução como uma atividade possível em seu livro A Social Construtivist Approach do Translator Training, mas não se aprofunda na questão. Curiosamente, André Lefevere sugeriu, no início da década de 1990, que "traduções [mais antigas] e/ou diferentes de um mesmo texto podem ser iluminadoras" (1991, p. 130) numa oficina de tradução. No mesmo artigo, ele argumenta que uma oficina de tradução não é o único método de se ensinar tradução; a atividade deve ser estudada considerando-se o lugar que ocupa na história literária

${ }^{3}$ Bibliografía de Interpretación y Traducción. Disponível em http://aplicacionesua.cpd.ua.es/tra_int/usu/buscar.asp

${ }^{4}$ Disponível (à época) em https://stjerome.co.uk/tsa/. N.T.: Posteriormente, houve uma fusão com a Translation Studies Bibliography (TSB), disponível em https://benjamins.com/catalog/tsa

${ }^{5}$ Ambas as pesquisas datam de 8 ago 2013. 
(LEFEVERE, 1991, p. 131), o que pode ter o efeito de criar uma dissociação entre as abordagens críticas e as práticas.

A retradução frequentemente é discutida em estudos mais gerais sobre a tradução, tais como The Translator's Invisibility, de Lawrence Venuti (1995, p. 205-224); Descriptive Translation Studies and Beyond (1995, p. 166); Is That a Fish in Your Ear?, de David Bellos (2011, p. 305-311); e Pour une critique des traductions: John Donne (1995, p. 40; 191-197). Nos volumes de Berman e Venuti, os estudos de caso sobre múltiplas traduções de um mesmo texto oferecem a esses autores a oportunidade de explorar as mudanças que as traduções sofreram ao longo do tempo e de contrastar diferentes abordagens tradutórias do mesmo texto. Considero que a ideia de múltiplas abordagens possíveis a um mesmo texto - gerando, consequentemente, múltiplas traduções - é central aos Estudos da Tradução como disciplina. Visto que sempre há bem mais de uma tradução possível para um texto, pode-se procurar saber por que um texto traduzido tomou aquela forma específica, permitindo aos estudiosos explorar essas causas a partir de uma série de ângulos diferentes.

Na sala de aula, como sugeriu Lefevere, a prática da retradução também oferece a oportunidade de explorar essas múltiplas causas e permite aos aprendizes refletir sobre suas próprias escolhas. A prática de Clive Scott em Translating Baudelaire (2000) e Translating Rimbaud's Illuminations (2006), embora baseada em textos literários, mostra que a retradução pode levar à reflexão crítica de diferentes formas. Scott analisa suas retraduções experimentais de textos canônicos por meio de diversas lentes críticas. A discussão sobre retradução pode ir além das argumentações de ordem linguística e textual, como bem demonstra David Bellos no seu capítulo sobre tradução literária em Is That a Fish in Your Ear? (2011, p. 305-311). Bellos discute a retradução em relação à questão dos direitos autorais e ao status comercial de textos literários, associando, assim, a prática tradutória a questões legais e ao mercado. Esse tipo de discussão em uma sala de aula pode ajudar os alunos a entender o papel da tradução na cultura contemporânea (ou mesmo em outras situações históricas, se os aprendizes estiverem analisando traduções produzidas em outro período). 
Neste artigo, desejo explorar de que forma a prática da retradução pode ser usada na sala de aula e como essa utilização diz respeito aos objetivos da formação de tradutores. Vou enfocar especificamente a formação em Estudos da Tradução no Reino Unido, por ser o ambiente que mais conheço, mas argumento que os resultados podem ser aplicados em outros contextos, uma vez que a formação de tradutores costuma ter objetivos similares. Inicialmente, pretendo discutir essas metas com referência à competência tradutória, para em seguida abordar de que forma a retradução pode unir teoria e prática e, por fim, sugerir exemplos práticos de atividades de retradução na sala de aula.

\section{Para que serve a formação de tradutores?}

A primeira pergunta a ser respondida é: quais são os objetivos de se ensinar a prática da tradução? Uma resposta básica seria que a formação de tradutores visa atualmente desenvolver a competência tradutória dos aprendizes. Respostas de outros períodos históricos podem ser bem diferentes: a tradução tem sido vista, tradicionalmente, como uma forma de aprimorar tanto a competência em língua estrangeira quanto a escrita na língua materna dos aprendizes. " "Competência tradutória" é, no entanto, um termo multifacetado que tem sido interpretado de muitas maneiras. Devido a restrições de espaço não é possível apresentar aqui um levantamento completo de todas as abordagens da competência tradutória, por isso vou me concentrar em duas definições: a definição "minimalista" de Anthony Pym (2003) e os objetivos e metas do Mestrado Europeu em Tradução (GAMBIER, 2009).

$\mathrm{O}$ artigo de Pym é uma resposta às dificuldades que cercam a definição de competência tradutória. Pym percorre as múltiplas definições do conceito, inclusive as asserções fundacionais feitas por Wilss (PYM, 2003, p. 482-3), antes de fazer um balanço de quantos autores evitaram a questão da competência tradutória (PYM, 2003, p. 484-5) ou a segmentaram em várias competências diferentes (PYM, 2003, p. 485-7). Ao tornar a

\footnotetext{
${ }^{6} \mathrm{Na}$ verdade, em 55A.C. Cícero (1997, p. 7) já defendia que a tradução é uma forma de aprender a arte da retórica. Abordagens mais recentes ao uso da tradução no aprendizado de línguas podem ser encontradas em Malmkjær (1998).
} 
competência tradutória multifacetada e detalhada, argumenta Pym (2003, p. 488), a teoria não consegue acompanhar as mudanças que ocorrem na profissão de tradutor, as quais, por sua vez, introduzem novas necessidades em termos de competências para os tradutores, tais como o uso de mídias eletrônicas, softwares de memória de tradução de ponta, modalidades tradutórias recentes etc. etc.

A solução de Pym é uma definição elegante e simples, que define a natureza do processo tradutório com base em duas habilidades:

- a habilidade de gerar uma série de mais de um texto-meta viável $\left(\mathrm{TM}_{1}, \mathrm{TM}_{2} \ldots \mathrm{TM}\right.$ ) para um dado texto-fonte (TF);

- a habilidade de selecionar apenas um texto-meta (TM) viável a partir dessa série, com rapidez e confiança fundamentada.

Essa definição de competência tradutória é interessante de adotar com relação à retradução por dois motivos. O primeiro deles é a forma pela qual ela pressupõe que a habilidade de gerar múltiplos textos-meta possíveis faz parte da competência tradutória. Essa possibilidade de versões múltiplas é, como argumentei antes, central aos Estudos da Tradução como disciplina. Há sempre mais de uma maneira de se traduzir um texto, como as retraduções bem demonstram na prática. A segunda parte da definição de Pym sugere que os tradutores devem escolher apenas uma solução - é isto que se espera dos tradutores: um texto limpo, bem revisado, em lugar de um texto cheio de barras e outros indicadores de soluções alternativas. No caso de uma retradução, uma série de soluções já foi usada: para que a tradução mais recente se diferencie das anteriores, as novas soluções devem ser distintas e identificáveis. O tradutor, então, precisa ser capaz de fazer escolhas com base em uma leitura crítica da tradução anterior, bem como em uma leitura do texto-fonte. A retradução, portanto, pressupõe uma abordagem crítica à práxis tradutória.

Esse tipo de habilidade crítica extrapola a definição minimalista de Pym, mas não ultrapassa os limites do que esperamos de nossos alunos. $\mathrm{Na}$ verdade, as diretrizes para a competência tradutória associadas ao Mestrado Europeu em Tradução (EMT, na sigla em inglês) requer que os aprendizes 
sejam capazes não só de "[dominar] a metalinguagem apropriada"7 (GAMBIER, 2009, p. 5), o que significa poder falar sobre suas próprias traduções empregando com precisão a terminologia desenvolvida no âmbito dos Estudos da Tradução, como também de "justificar [suas próprias] escolhas e decisões tradutórias"8 (GAMBIER, 2009, p. 5). As competências do EMT têm um alcance mais amplo, incluindo uma combinação de habilidades linguísticas, tecnológicas, interculturais e de pesquisa, além da competência de prestar serviços de tradução - a lista é longa e pode ser lida com um retrato das necessidades ou expectativas da indústria da tradução nos últimos anos. Da mesma forma, espera-se que os mestrados no Reino Unido sigam os parâmetros de referência estabelecidos pela Quality Assurance Agency for Higher Education - QAA (Agência de Garantia de Qualidade para o Ensino Superior), o que inclui conhecimentos informados pela "vanguarda do seu campo disciplinar"9 (QAA, 2008, p. 20), novamente destacando a relação entre teoria e prática.

Em relação à retradução, a determinação do EMT de que os aprendizes sejam capazes de explicar e justificar suas próprias soluções tradutórias é importante. Como já mencionei, a retradução pressupõe uma abordagem crítica a uma tradução anterior: o aprendiz deve ser capaz de encontrar formas de traduzir que se diferenciem da tradução atual e justificar essas escolhas, ou então, caso ele ou ela opte por manter as mesmas soluções, que justifique por que as considera tão adequadas. $\mathrm{O}$ uso ativo da teoria para fazer isso implica empregar a metalinguagem correta, bem como dialogar com as pesquisas mais recentes, atendendo aos objetivos do EMT e aos parâmetros de referência da QAA.

Minha proposta aqui é formular um modelo da retradução como "prática crítica". Elspeth kydd [sic] emprega o termo "prática crítica" em relação ao cinema (2011); eu o reaproprio para a retradução, embora acredite que ele também pode ser aplicado à tradução em geral. Kydd define prática crítica como "um processo que explora a integração e a interseção entre a

\footnotetext{
${ }^{7}$ N.T. "[master] the appropriate metalanguage"

${ }^{8}$ N.T. "justify [their own] translation choices and decisions"

${ }^{9}$ N.T. "the forefront of their academic discipline"
} 
análise crítica de filmes e os aspectos práticos da produção cinematográfica"10 (KYDD, 2011, p. 1).

Essa concepção não está distante da minha noção de retradução e, portanto, eu poderia reescrever a definição de kydd aplicando-a a essa prática: "um processo que explora a integração e a interseção entre a análise crítica de traduções e os aspectos práticos do traduzir"11.

Esse processo necessariamente inclui uma combinação de consciência teórica com consciência crítica, pois de que outra forma é possível realizar uma "análise crítica"? Da mesma forma, a prática é fundamental. Retornando à minha pergunta inicial, ou seja, como conjugar teoria e prática no ensino da tradução, me parece que a resposta é: por meio de uma prática tradutória crítica. Além disso, o uso de metalinguagem e as justificativas para a tradução, como determinam as diretrizes do EMT (entre outros requisitos), são contemplados, visto que a prática da tradução está associada a uma conscientização teórica que pode ser explicada. Até mesmo a definição mínima de competência de Pym, como já argumentei, sugere essa consciência crítica por meio da escolha justificada de uma solução viável.

Em resumo, portanto: a formação do tradutor deve promover o desenvolvimento da competência tradutória, que inclui as competências centrais de criar e selecionar soluções tradutórias apropriadas para um dado texto-fonte e a capacidade de justificar a escolha de uma solução específica em detrimento de outras possibilidades. Para tanto, é necessário ter algum tipo de consciência crítica, que pode ser explicitada, conforme argumento, nos exercícios de retradução, que se tornam uma forma de "prática crítica". Na próxima seção, pretendo discutir algumas possibilidades práticas para esse tipo de exercício e mostrar como elas se relacionam à aprendizagem.

\section{Exercícios de retradução}

Há diversas formas possíveis de se incorporar a retradução ao currículo de tradução. As possibilidades vão desde leituras de múltiplas traduções, que é

\footnotetext{
${ }^{10}$ N.T. "a process that explores the integration and intersection between the critical analysis of films and the practical aspects of filmmaking"

${ }^{11}$ N.T. "A process that explores the integration and intersection between the critical analysis of translations and the practical aspects of translating.
} 
por onde começarei neste trabalho, até usos e projetos mais práticos. A ênfase aqui é no professor como um "planejador de recursos" (ROGERS, 1989, p. 47), em lugar de algum tipo de transmissor de conhecimentos; em outras palavras, estou operando no contexto de um modelo de tradução centrado no aprendiz, tal como proposto por Kelly (2005) e outros teóricos da pedagogia da tradução. Em consonância com a teoria do "alinhamento construtivo" (BIGGS; TANG, 2011, p. 97-100), as atividades aperfeiçoam a competência tradutória no que tange a produzir e descrever uma tradução. Os aprendizes desenvolvem seu entendimento por meio da prática e da reflexão.

A aplicação inicial da retradução na formação de tradutores não constitui, na verdade, um exercício prático de retradução e, sim, um exercício de leitura. A leitura é certamente uma habilidade prática, mas o foco aqui é levar os aprendizes a elaborar comentários sobre diferentes traduções. Isso não é traduzir, mas ajuda a criar as bases para entender como a tradução funciona e a praticar a descrição e análise de traduções por meio do emprego da metalinguagem adequada. $\mathrm{O}$ exercício é bastante flexível: pode ser realizado na sala de aula com alguma preparação prévia ou leituras preliminares.

Os aprendizes recebem dois ou mais textos que são traduções do mesmo texto-fonte. Elas podem vir acompanhadas do respectivo texto de origem; até em uma sala de aula multilíngue (isto é, na qual nem todos os aprendizes de tradução trabalham com o mesmo par de línguas) esse recurso pode ser útil, uma vez que alguns estudantes poderão consultar o texto-fonte e fazer comentários que o levem em consideração. A seguir, os aprendizes são instados a ler as diferentes traduções do texto e refletir sobre o que as torna distintas. Essa atividade poderá ser desenvolvida individualmente ou em grupos.

Uma vez identificadas determinadas diferenças, a melhor forma de associar a teoria à prática é perguntar por que essas diferenças aparecem nos textos: quais as causas das decisões dos tradutores? Refletir sobre essa questão pode conduzir a todo tipo de resultado, dependendo do nível dos aprendizes e do tempo disponível. Poderia, por exemplo, levá-los a se aprofundar no conhecimento dos períodos cronológicos em que as traduções 
foram feitas; a buscar informações sobre os tradutores, o que contemplaria inclusive a leitura de afirmações que eles possam ter feito sobre as traduções; a fazer pesquisas sobre gênero textual; e assim sucessivamente. Já nessa etapa existe a possibilidade de extrapolar a análise textual e chegar até a análise histórica e sociológica, permitindo que os aprendizes explorem as pesquisas mais recentes nesse campo. Além disso, parece uma boa oportunidade para os estudantes discutirem a Teoria do Escopo (por exemplo, VERMEER, 2012; NORD, 1997) e como ela se relaciona a traduções concretas: ao analisar a finalidade de cada texto-meta, os aprendizes poderão entender melhor como as traduções são produzidas para diferentes públicos e situações.

Uma segunda forma de exercício baseado em retradução pode ser denominada "retradução velada". Proponho dar-lhe esse nome por não se apresentar de saída como um exercício de retradução mas, sim, como a tradução de um texto. Essa atividade é mais apropriada para oficinas específicas de um idioma do que para turmas multilíngues. Primeiramente os estudantes recebem um texto curto para traduzir, sendo que o TF já tinha sido traduzido anteriormente, mas essa informação não é divulgada. A tradução é então feita (em casa ou na sala de aula) e, a seguir, discutida pela turma, como acontece normalmente nas oficinas específicas de cada idioma. Os aprendizes identificam diferenças entre suas próprias traduções, observam as soluções dos colegas e passam a compreender melhor o texto e suas traduções possíveis. Esta é uma excelente oportunidade para os integrantes da turma ouvirem os comentários dos colegas sobre o seu trabalho. Fazer comentários sobre as traduções dos pares pode ajudar a aumentar as próprias competências dos aprendizes (BIGGS; TANG, 2011, p. 147), assim como oferecer-lhes a oportunidade de receber feedback sobre a sua escrita, o que é produtivo (ver WANG; HAN, 2013 para uma discussão sobre comentários de pares no contexto da formação de tradutores). Após a discussão da tradução, os aprendizes recebem a tradução já publicada e são instados a discuti-la: quais soluções funcionam bem? O que eles fariam de modo diferente? Por que eles acham que o/a tradutor/a optou por aquelas soluções específicas? 
Como os aprendizes já tinham produzido e discutido suas próprias traduções, há menos probabilidade de considerarem a tradução publicada como a versão definitiva. Podem encará-la como apenas uma dentre diferentes soluções possíveis. Ao analisá-la, eles desenvolvem suas próprias habilidades críticas, refletindo tanto sobre as causas da tradução como sobre outros elementos textuais, mais imediatos. Uma dificuldade relacionada a essa tarefa é que os aprendizes têm pouco tempo para analisar o texto, já que o recebem na sala de aula, o que pode gerar comentários por vezes superficiais. Uma saída possível para contornar esse risco é pedir aos aprendizes que elaborem seus comentários sobre a tradução publicada como tarefa de casa de uma semana para a outra, ou ainda permitindo que eles postem seus comentários em um site da internet ou em um ambiente virtual de aprendizagem. Essa solução permite uma reflexão mais aprofundada sobre o texto, além de poder ser usada como ponto de partida da discussão a ser conduzida na oficina seguinte. Uma segunda dificuldade pode surgir se os aprendizes não se sentirem à vontade para criticar um texto publicado. Mas é possível, até certo ponto, contorná-la, apresentando-se a tradução publicada depois que os estudantes tiverem produzido suas próprias traduções e, consequentemente, já elaborado uma solução viável. Além disso, pode-se aumentar o foco na causalidade no decorrer da discussão sobre os textos, fazendo, dessa forma, com que as críticas soem menos negativas e enfatizando mais a busca por entender como um outro tradutor tomou suas decisões. Dessa forma, os aprendizes se sentem incentivados a historicizar suas próprias traduções e a ver as discrepâncias entre o seu próprio trabalho e a tradução publicada não como erros, mas, sim, como uma evidência de mudanças nas normas ou uma diferença de foco.

Um terceiro exercício pode ser denominado, com uma dose de cautela, "retradução propriamente dita". Nesse caso, os aprendizes recebem textos-fonte e textos-meta publicados, a fim de produzir uma nova tradução que seja distinta da anterior. Isso é algo que os tradutores frequentemente precisam fazer, sobretudo na tradução literária (BELLOS, 2011, p. 307), muito embora, como já comentado no início deste artigo, a retradução aconteça em outros campos também. Esse exercício pode ser visto como uma tarefa 
autêntica (BIGGS; TANG, 2011, p. 212) que está claramente associada à aprendizagem (RAMSDEN, 2003, p. 204).

A tradução de cada aprendiz deve vir acompanhada de um comentário apontando quais as diferenças em relação à tradução já existente. O comentário pode ser oral ou escrito, dependendo das necessidades da turma. Juntos, o comentário e a tradução unem a teoria e a prática da tradução, podendo facilmente impactar a formação de tradutores. Em termos de comentários escritos, reflexões elaboradas por Marilyn Booth (2008) e por Cristina Marinetti e Margaret Rose (2013), além dos volumes de Clive Scott (2000; 2006), podem ser usados para ajudar os aprendizes a entender como escrever a respeito de suas próprias traduções. É evidente que uma simples tradução acompanhada de comentário também pode associar teoria e prática (ver MARINETTI; ROSE, 2013), mas o meu argumento é que uma retradução com comentário força os aprendizes a se envolver de forma crítica com o trabalho de outros tradutores, o que é coerente com a minha concepção de tradução como prática crítica. O exercício pode ser usado para gerar avaliação formativa e somativa, tanto pelos pares quanto pelo professor.

Esse tipo de exercício pode ser aplicado em uma oficina específica de um idioma ou em uma sala de aula multilíngue. No primeiro caso, presumese que todos os aprendizes podem ler o texto-fonte e produzir suas próprias traduções a partir dele. Quando traduzem com acesso a traduções já existentes, eles descobrem que têm menos opções possíveis: uma das soluções viáveis para cada problema já foi escolhida na tradução publicada. Não é necessário que sua tradução seja completa e deliberadamente distinta da tradução anterior, mas deve haver diferenças perceptíveis ao longo do texto. Os aprendizes estão, portanto, participando de uma forma de exercício de escrita restritivo, visto que suas opções são limitadas até certo ponto. ${ }^{12}$ Ao mesmo tempo, eles estão mobilizando sua competência tradutória no sentido da definição de Pym (2003), de criar e escolher soluções viáveis a partir de leituras críticas do texto-fonte e do texto-meta pré-existente. O exercício é, portanto, uma combinação de leitura crítica e reescrita criativa.

\footnotetext{
${ }^{12}$ Esse exercício é diferente daqueles descritos por O'Sullivan (2012), de caráter oulipiano, na medida em que há menos ênfase em recriar as coerções formais do texto-fonte.
} 
Ao discutir suas soluções na sala de aula ou em comentários, os aprendizes precisarão justificar suas próprias escolhas: seja qual for a maneira de fazêlo, certamente envolverá uma compreensão teórica da tradução que precisará ser explicitada. Até poderá surgir a velha resposta "soa melhor assim", mas é possível eliminá-la por meio de novos questionamentos.

Em turmas multilíngues, o exercício poderá funcionar melhor se os aprendizes puderem escolher seus textos-fonte. Visto que o restante da turma não conseguiria entender a tradução isoladamente, os aprendizes precisam explicar sua leitura do texto, oferecendo traduções e interpretações formal e estruturalmente equivalentes às anteriores, as chamadas gloss translations e gloss interpretations, juntamente com as suas próprias soluções. Mais uma vez combinam-se aqui processos criativos e críticos, levando os participantes a uma postura reflexiva sobre seu próprio trabalho.

Esse exercício pode ser ampliado de modo a configurar projetos nos quais a seleção dos textos-fonte fica a critério dos aprendizes, com a orientação de que esses textos já tenham sido traduzidos e que cada aprendiz seja capaz de justificar sua retradução. Outras formas de ampliação podem incluir a solicitação de algum tipo de viés na retradução, como um viés político (por exemplo, feminista). Isso pode levar os estudantes a explorar teorias e práticas de tradução distantes das suas preferências pessoais. Essa estratégia pode ser usada nas áreas em que a retradução é menos comum, como, por exemplo, a tradução científica ou a tradução audiovisual: nesse caso, o efeito será o de ressaltar a ação crítica que aquele aprendiz está desenvolvendo precisamente porque a retradução é menos comum nessas áreas e, portanto, requer maior reflexão. A tarefa pode ser proposta na medida em que o professor e os aprendizes se mostrarem dispostos a realizála.

Concluindo, refletir sobre retradução e praticá-la oferece, portanto, o tipo de associação entre teoria e prática que é parte integrante dos Estudos da Tradução. Isso pode abrir caminho para todo tipo de investigação, desde textual até histórica e sociológica, oferecendo aos estudantes a oportunidade de se envolver tanto com as pesquisas mais recentes no âmbito da disciplina, como também com a sua própria prática. Dá aos aprendizes a oportunidade de mostrar, por meio da prática e de comentários reflexivos, suas leituras de 
um texto-fonte e de versões traduzidas já existentes. Ao descrever suas próprias retraduções, os aprendizes precisam recorrer à metalinguagem sobre tradução mais apropriada, além de mostrar que conhecem os conceitos teóricos sobre tradução. Dessa forma, a retradução pode ser considerada alinhada, de forma construtiva, aos objetivos da formação de tradutores.

De muitas formas, os exercícios que se baseiam na prática da retradução podem ser moldados de acordo com os interesses dos aprendizes. Eles podem preferir o caminho das retraduções experimentais, ao estilo de Clive Scott $(2000,2006)$, ou se manter mais próximos do texto-fonte, dependendo do que considerarem relevante para o texto que estão traduzindo. A retradução não precisa se restringir a textos literários, e o exercício pode ser aplicado a textos de outros campos do saber. Em todas as situações, no entanto, essa atividade incentiva uma prática tradutória crítica, informada por uma leitura crítica de outras traduções e abordagens teóricas.

\section{Referências}

AALTONEN, Sirkku. Retranslation in Finnish Theatre. Cadernos de Tradução 1 (11): 141-159, 2003. Disponível em https://periodicos.ufsc.br/index.php/traducao/article/view/6180/5735.

BAKER, Mona. In Other Words. 2nd edition. London/New York: Routledge, 2011.

BELLOS, David. Is That a Fish in Your Ear? Translation and the Meaning of Everything. London: Particular Books, 2011.

BERMAN, Antoine. Pour une critique des traductions: John Donne. Paris: Gallimard, 1995.

BIGGS, John; TANG, Catherine. Teaching for Quality Learning at University. 4th edition. Maidenhead: Open University Press/McGraw-Hill Education, 2011.

BOOTH, Marilyn. Translator vs. author (2007). Translation Studies 1 (2): 197-211, 2008. 
CICERO, Marcus Tullius. Translating Greek Orations into Latin. In: ROBINSON, Douglas (ed.). Western Translation Theory from Herodotus to Nietzsche. Manchester: St Jerome, 1997, p. 6-12.

DEANE-COX, Sharon. Confronting the Retranslation Hypothesis: Flaubert and Sand in the British Literary System. Unpublished PhD Dissertation. University of Edinburgh, 2011.

DOLLERUP, Cay; LODDEGAARD, Anne (eds.). Teaching Translation and Interpreting: Training, Talent and Experience. Amsterdam: John Benjamins, 1992.

GAMBIER, Yves. Competences for professional translators, experts in multilingual and multimedia communication. EU - DG Translation European Masters in Translation (EMT), 2009. Disponível em: http://ec.europa.eu/dgs/translation/programmes/emt/key_documents/emt_ competences_translators_en.pdf

GILE, Daniel. Basic Concepts and Models for Interpreter and Translator Training. Amsterdam: John Benjamins, 1995.

GONZÁLEZ Davis, Maria. Multiple Voices in the Translation Classroom. Amsterdam: John Benjamins, 2004.

HUNG, Eva (ed.). Teaching Translation and Interpreting 4. Amsterdam: John Benjamins, 2002.

KEARNS, John (ed.). Translator and Interpreter Training: Issues, Methods and Debates. London: Continuum, 2008.

KELLY, Dorothy. A Handbook for Translator Trainers. Manchester: St Jerome, 2005.

KIRALY, Don. A Social Constructivist Approach to Translator Training: Empowerment from Theory to Practice. Manchester: St Jerome, 2000.

KOSKINEN, Kaisa; PALOPOSKI, Outi. Retranslations in the Age of Digital Reproduction. Cadernos de Tradução 1 (11): 19-38, 2003. Disponível em: https://periodicos.ufsc.br/index.php/traducao/article/view/6175/5730

KUSSMAUL, Paul. Training the Translator. Amsterdam: John Benjamins, 1995. 
KYDD, Elspeth. The Critical Practice of Film: An Introduction. Basingstoke: Palgrave Macmillan, 2011.

LEFEVERE, André. Translation and Comparative Literature: The Search for the Centre. TTR: Traduction, Terminologie, Rédaction 4 (1): 129-144, 1991.

MALMKJÆR, Kirsten (ed.). Translation and Language Teaching: Language Teaching and Translation. Manchester: St Jerome, 1998.

MARINETTI, Cristina; ROSE, Margaret. Process, practice and landscapes of reception: An ethnographic study of theatre translation. Translation Studies 6 (2): 166-182, 2013.

MONTI, Enrico. Introduction: La retraduction, un état des lieux. In: MONTI, E.; SCHNYDER, P. (eds.). Autour de la retraduction: Perspectives littéraires européennes. Paris: Orizons, 2011, p. 9-20.

MONTI, Enrico; SCHNYDER, Peter (eds.). Autour de la retraduction: Perspectives littéraires européennes. Paris: Orizons, 2011.

NORD, Christiane (1997). Translating as a Purposeful Activity: Functionalist Approaches Explained. Manchester: St Jerome.

O'DRISCOLL, Stephen. Retranslation through the Centuries: Jules Verne in English. Bern: Lang, 2011.

O'SULLIVAN, Carol. Playing With(out) the Dictionary. Using Constrained Literature in the Development of Transferable Skills for Translators. The Interpreter and Translator Trainer 6 (2): 237-265, 2012.

PYM, Anthony. Redefining Translation Competence in an Electronic Age. In Defence of a Minimalist Approach. Meta 48 (3): 481-497, 2003.

QAA. The framework for higher education qualifications for England, Wales and Northern Ireland, 2008. Disponível em: http://www.qaa.ac.uk/Publications/InformationAndGuidance/Documents/ FHEQ08.pdf

RAMSDEN, Paul. Learning to Teach in Higher Education. 2nd edition. London: Routledge Falmer, 2003. 
ROBINSON, Douglas. Becoming a Translator: An Introduction to the Theory and Practice of Translation. 3rd edition. London/New York: Routledge, 2012.

ROGERS, Jenny. Adults Learning. 3rd edition. Milton Keynes: Open University Press, 1989.

SCOTT, Clive. Translating Baudelaire. Exeter: Exeter University Press. 2000.

SCOTT, Clive. Translating Rimbaud's Illuminations. Exeter: Exeter University Press, 2006.

SUSAM-SARAJEVA, Şebnem. Multiple Entry Visa to Travelling Theory. Target 15 (1): 1-36, 2003.

TAHIR GÜRÇAĞLAR, Şehnaz. Retranslations. In: BAKER, M.; SALDANHA, G. (eds.). The Routledge Encyclopedia of Translation Studies. 2nd edition. London/New York: Routledge, 2009.

TOURY, Gideon. Descriptive Translation Studies and Beyond. Amsterdam: John Benjamins, 1995.

VENUTI, Lawrence. The Translator's Invisibility: A History of Translation. London/New York: Routledge, 1995.

VERMEER, Hans J. Skopos and Commission in Translation Theory. In: VENUTI, L. (ed.). The Translation Studies Reader. 3rd edition. New York/London: Routledge, 2012, p. 191-202.

WANG, Kenny; HAN, Chong. Accomplishment in the multitude of counsellors: Peer feedback in translation training. Translation \& Interpreting 5 (2): 62-75, 2013.

XU, Jianzhong. Retranslation: Necessary or Unnecessary. Babel 49 (3): 193202, 2003.

\section{Resumo}

Este artigo aborda a questão de como relacionar a teoria à prática no ensino da tradução. A retradução é vista como uma prática crítica (KYDD, 2011) que associa engajamento crítico a traduções concretas, e a teoria à prática. Essa 
reflexão crítica faz parte da competência tradutória, tanto na formulação minimalista de Pym (2003) como nas diretrizes do Mestrado Europeu em Tradução. Pode-se, portanto, considerar que a retradução ajuda os estudantes a alcançar o tipo de consciência crítica que integra a competência tradutória. O trabalho sugere uma série de atividades práticas de aprendizagem que se utilizam da retradução. Tais atividades vão de análises de retraduções do mesmo texto à realização de retraduções comentadas, em que os estudantes devem explicar os procedimentos adotados. Cada uma delas oferece maneiras de extrapolar a crítica textual, de modo a contemplar questões teóricas mais amplas.

Palavras-chave: Retradução; Pedagogia da tradução; Prática reflexiva; Competência tradutória; Elaboração de comentários

\begin{abstract}
This article addresses the question of how to relate translation theory to translation practice when teaching translation. Retranslation is viewed as a critical practice (KYDD, 2011) that integrates critical engagement with existing translations and theory into practice. This critical reflexion is part of translation competence, both in Pym's (2003) minimalist formulation and the European Master's in Translation guidelines. Retranslation can therefore be seen to help students achieve the sort of critical awareness that is part and parcel of translation competence. A series of practical learning activities are suggested that use retranslation. These range from analyses of retranslation of the same text to commented retranslations that ask the students to explain their own process. Each of these offers ways of going beyond textual criticism to engage with wider theoretical concerns.
\end{abstract}

Keywords: Retranslation; Translation Pedagogy; Reflexive Practice; Translation Competence; Commentary Writing 